\title{
Histories and Realignments: Museum Anthropology Review in a New Era*
}

\author{
Jason Baird Jackson
}

\begin{abstract}
In an editorial, Museum Anthropology Review editor Jason Baird Jackson discusses the history of the journal as a context for explaining plans to reorient it to focus more closely on the work of the Mathers Museum of World Cultures and its museum and community partners; reducing the amount of unsolicited content published and increasing invited content arising from the research, exhibitions, and outreach work of the museum and its collaborators.
\end{abstract}

[Keywords: editors; ethnological museums; publications. Keywords are derived from the American Folklore Society Ethnographic Thesaurus, a standard nomenclature for the ethnographic disciplines.]

Museum Anthropology Review (MAR) entered the world under very different conditions from those that shape it today. MAR was not born of a slow, deliberative process pursued collaboratively and addressing abstract goals such strengthening the fields of museum anthropology and material culture studies. MAR was born in a reactive way and was improvisationally shaped initially in response to a rather complicated set of factors that were then, and that are even now, hard to sort out and harder still to fully explain. MAR was begun at a time in which another journal-Museum Anthropology-faced some paradoxical and difficult circumstances. MAR's origins are closely entangled with that older and more established journal.

I had the honor of serving a term as editor of Museum Anthropology, the journal of the Council for Museum Anthropology, between 2005 and 2009. For those who are old enough to remember finding print issues of that journal in their mailboxes, these were the green covered issues that fell between those with white covers and those with fully redesigned brown covers. When, in 2005, I began work towards publishing my first issue as Museum Anthropology's editor in 2006, there was little potential content on hand and I had to prime the pump by rapidly soliciting not only articles but reviews of various kinds. I knew that reviews could help me get out of a jam because they can be solicited, written, and readied for publication more quickly than can peer-reviewed articles. You can see the fruits of this strategy in Museum Anthropology 29 (1); my first issue as editor. In it, I initiated the practice of publishing digital exhibition and media reviews (Jackson 2006), and that issue featured ten such reviews together with three exhibition reviews and five book reviews. The other early issues were similarly review-heavy, as articles moved through the peer-review

\footnotetext{
* This editorial was accepted for publication in Museum Anthropology Review on February 6, 2019 on the basis of review by two members of the editorial board. The work is licensed under the Creative Commons Attribution 4.0 International License. To view a copy of this license, visit http://creativecommons.org/licenses/by/4.0.
} 
pipeline. It was not until 2008, with volume 31(2), that articles dominated an issue published during my editorship.

During my time editing Museum Anthropology, the acceptance rate for articles fell steadily, as more and more were reviewed and fewer and fewer could be accommodated within the limited physical pages of the print-format journal and its two-yearly issues. ${ }^{1}$ At the same time, the work of publishing varied reviews was going well and my sense was that these reviews were serving the field. This was especially true for the new digital reviews and for exhibition reviews, as these treatments of work pursued by our colleagues were particularly rare on the journal landscape. As remains true, exhibition reviews are sometimes the only way that museum exhibitions are inscribed and, thereby to a degree, preserved in the scholarly record. They have special value for the field of museum anthropology.

The Council for Museum Anthropology is a constituent section of the American Anthropological Association (AAA). The period of my Museum Anthropology editorship was one of great turmoil and uncertainty in the publishing work of the AAA. Recounting the history of AAA publishing in the period of my editorship is too great a task, but I need to evoke it to tell the story of Museum Anthropology and in turn Museum Anthropology Review. As the pages of Museum Anthropology became increasingly hard to get into, thought was given to ways of making available more content than was then being published between the covers of the print journal. In the period prior to the AAA's partnership with Blackwell (a.k.a. Wiley-Blackwell, Wiley), constituent AAA sections, such as the Council for Museum Anthropology, paid directly for the pages they published. The AAA's journal system faced a number of stresses during these years, one of which was financial. While it would have been desirable from some points of view to expand the number of issues of Museum Anthropology then being published, from two to three or even four per year, this was not at that moment an affordable possibility. The great fear of that era was that the section would not be able to continue publishing the journal at the scale that it was then publishing it or, worse still, that the journal would completely disappear for financial rather than editorial reasons.

In that period, the American Ethnological Society, another AAA section, had begun an experiment of publishing its similar overflow of reviews online, outside the print edition of the American Ethnologist. The idea behind this, prior to much understanding of open access issues in anthropology, was that these reviews would be freely available on the internet and that once the AAA's AnthroSource portal was fully developed, this content could be reunited with the other American Ethnologist content and also preserved in a more robust way (within AnthroSource) even thought it was not being archived in print format. The AAA publishing staff recommended that Museum Anthropology pursue something similar for the review content that could not be fit within the bounds of the journal's 160 or so pages per year. This idea was one factor that shaped the birth of Museum Anthropology Review.

The financial pressures faced then by the Council for Museum Anthropology and other AAA sections was also a key factor distinct from the question of how much content could be squeezed into two issues of the journal. For reasons that were well-founded, the section leadership during the first half of my editorship became concerned that continued publication of Museum Anthropology might become impossible because the costs to the 
section were quickly becoming too great. Publication was then dependent on spending quickly diminishing financial reserves. The trendlines for Museum Anthropology and numerous other AAA section journals were not looking positive. The causes of these difficulties are multiple and I do not wish to unpack them here. They included revenues (lower than projected) and expenses (higher than projected) associated with AnthroSource (as it then was, as a new project launched by the AAA with initial funding from the Mellon Foundation). Also relevant were the ways that the AAA's publishing partnership with the University of California Press was constructed (on a fee-for-services basis). The complexities of the section system and the ways that section finances then worked were also part of the mix. The AAA leadership sought to address these problem in a number of ways. The possibility of the AAA making financial loans to its sections while everyone waited for revenues to rise was considered but not implemented. Instead, the AAA entered in a very differently structured publishing partnership with Blackwell (soon to merge with Wiley). The partnership with Blackwell became controversial and I opposed it, but there is no doubt that it stabilized the financial picture for the many journals published by the AAA sections and for the AAA publishing program as a whole.

Leaders of the sections, such as those of the Council for Museum Anthropology, had no way of knowing that this new era of corporate partnership-based financial stability was on the horizon. In the period prior to the Blackwell (Wiley) partnership, things looked dire. As editor, I was asked by the Council for Museum Anthropology board to explore ways of preserving a publishing outlet for the field of museum anthropology in the event that the then-severe financial pressures ended Museum Anthropology as we knew it. Might the journal, for instance, be published only online? If so, at what cost? How might it be preserved? Would authors accept such a journal? This was a time of increased discussion of open access scholarly publishing and of the affordances that digital strategies in general might offer those interested in publishing scholarly content. It was at the request of the Council's board that I began learning about such things and reporting back on my findings. These explorations linked up with the idea of publishing the "overflow" of reviews online, following the example of the American Ethnologist/American Ethnological Society.

Like the American Ethnological Society, the Council for Museum Anthropology has a history independent of the American Anthropological Association. The Council and its journal began before it joined the AAA as a constituent section. Joining with the AAA had then, and still has, support, but the merger remained in living memory when I was the Museum Anthropology editor. Even those museum anthropologists who followed the Council into its AAA era understood that the merger had had costs and that members had been lost in the process. This fact arose from the dual nature of professional practice among museum anthropologists, particularly those based in museums. Such colleagues may have had the time and resources to orbit around both the AAA and the American Alliance of Museums (AAM), but in actuality some museum anthropologists fell away from Council involvement because, while the Council was relevant to them, the AAA was not. Their larger home was the museum field, as represented by the AAM. This memory became reactivated during the time that the journal, and therefore the section, was under financial pressure within the larger AAA context. Voices arose in the membership asking if the time was right for the section to exit the AAA. I think that I stayed neutral on this point, but as editor I was already 
charged with helping the Council figure out where things were and where they were going relative to its publishing work and the financial and organizational implications of that work. For those who wanted the Council to contemplate exiting the AAA, these investigations took on an additional dimension. It was quickly realized that upon joining the AAA, the Council for Museum Anthropology signed over its name, journal, and organizational identity to the AAA. While the AAA could have, in this scenario, granted the membership of the Council permission to exit and to take its assets with it, this seemed unlikely to those who then weighed this contingency. In that context, my fact-finding (for some active in the Council at least) took on additional relevance. One thing that I was helping (some) contemplate was how a new journal aligned with a new post-AAA organization of museum anthropologists might come to exist.

In hindsight, this all seems like a blur. A lot happened and also a lot did not happen in the space of just a few years that felt beset by uncertainty and crisis. The AAA publishing program transformed in a dramatic way in this period. The partnership with the University of California Press had been one in which the AAA directed its own publishing work and turned to the press to provide contracted services for which they were paid à la carte. Both risks and control were retained by the AAA and this had real consequences for AAA (and also for the University of California Press). AnthroSource, as initially envisioned as a revenuegenerating resource catering to subscribing libraries, did not achieve initial revenue goals but the costs associated with it, and with the continued publication of print issues for members and libraries, were fixed. The relationship with Blackwell (Wiley) was and remains very different, with the publisher assuming a greater level of risk and receiving a proportional share of profits (rather than fixed fees) from what amounts to a joint venture. While AnthroSource continued to have a virtual existence (aimed primarily at members), most libraries obtained (and now obtain) AAA journal content as part of much larger aggregations of Wiley published and co-published content, delivered through Wiley Online Library. Happily, in my view, the Council for Museum Anthropology did not exit the AAA. Museum Anthropology was not forced out of existence for financial reasons. The AAA adopted an approach to publishing focused on the sustaining of its entire portfolio of journals, including both those that are strong revenue generators and those that are not (Nichols, Perley, and Schmid 2015; AAA 2019). Interestingly, Museum Anthropology exited the period that I am evoking as one of the stronger AAA journals as measured by use, acceptance rate, and other measures (Colwell-Chanthaphonh and Nash 2010).

Earlier in this period, the AAA publishing staff member who had encouraged me to continue soliciting and editing reviews above the carrying capacity of the print edition of Museum Anthropology departed the Association and a new staff member, hired from outside the AAA, briefly led the AAA publishing department. In a rapidly changing context filled with uncertainties, this colleague discouraged rather than encouraged free, online publication separate from the journal itself. I understood the logic of this alternative approach, but I had amassed many reviews that needed a home and the other issues evoked above were in play. ${ }^{2}$ It was in this context that I first experimented with publishing reviews-with the consent of their authors-on the blog (weblog) that I had earlier established to support the work of the journal. That blog remains active as the blog for the Council as a whole. Publication of this small number of reviews met with approval and, again in the contexts evoked above and with 
the knowledge of the Council's leaders, I started Museum Anthropology Review as a simple site using the WordPress.com blogging platform. The name was chosen in part because of the initial focus on reviews and in part because, had Museum Anthropology ceased publication and/or the Council left the AAA, the name would retain a sense of familiarity and connection to the Council and the journal from which it spun off.

The blog-based version of Museum Anthropology Review lasted for one year (2007). In that year, four review essays, one obituary, two museum reviews, one film and video review, one digital exhibition review, and fifty book reviews were published. In a February 21, 2008 press release, Indiana University announced what came next (Indiana University 2008). Museum Anthropology Review became the first open access journal to be published by the Indiana University Libraries. This step was part of a larger journey in which the library on my home campus was becoming deeply involved in a range of open access initiatives, and today the library partners in the publishing of fifty such journals, including other anthropology, folklore, and ethnology titles. As noted in my editor's report for Museum Anthropology, submitted in late fall 2007, it was in that year that the work of filling the remaining Museum Anthropology issues of my term was essentially completed. In 2007, the acceptance rate for articles reached $29 \%$ and it would be $21 \%$ in 2008. Manuscripts received in 2009 were reviewed by the journal's next editors (Jackson 2007).

It was in this moment that Museum Anthropology Review became distinct from Museum Anthropology. I was in the "cleanup and prepare to exit" phase of my editorship of Museum Anthropology. The remaining content for my final issues was in place and the Council's board recruited two outstanding colleagues-Chip Colwell and Stephen Nash-to succeed me. Their roles were made public in December 2008 (Jackson 2008, Fowler 2008, ColwellChanthaphonh and Nash 2008) and they formally began work in July 2009, although they were diligent in working with me during the handoff and in preparing for their own successful term as co-editors. In coordination with the editors-designate, I was extremely conservative in accepting articles during the final phase of my editorship so as to allow them the opportunity to shape Museum Anthropology in accord with their goals. I was also cautious in the initial transition about including peer-reviewed articles in Museum Anthropology Review so as to minimize the muddying of the waters during the period of overlap when MAR was taking on its own identity and I was handing on Museum Anthropology. I am thankful that the Council for Museum Anthropology leadership supported my proposal to continue editing Museum Anthropology Review distinct from Museum Anthropology at the end of my editorship.

While Museum Anthropology Review was created as an overflow space for, or as a possible plan B successor to, Museum Anthropology, its nature changed after my Museum Anthropology editorship concluded. Beginning in 2010, we might see my work on MAR as a kind of controlled experiment on the nature and possibilities of open access publishing. Having previously edited Museum Anthropology, my goal with Museum Anthropology Review was to serve the same field that Museum Anthropology served while holding the editorial factors as close to constant as I could while seeing what the implications of a very different business and distribution model would be. If I could, I wanted to compare Museum Anthropology and Museum Anthropology Review in a side-by-side way. Museum Anthropology 
Review was different in that it was not a society journal, it was freely available to all interested readers, and it was published with help from a university library rather than from a commercial or university press. It had no subscribers or cash flow, but it would have as many readers as interest and internet access would allow. Trying to preserve the comparative set, Museum Anthropology Review would also publish two issues per year. I would use the same peer-review standards and practices that I had used with Museum Anthropology and that I anticipated the Museum Anthropology editors who followed me would be using.

I have not made the most of this comparative evidence, at least not yet. But the experiences of editing Museum Anthropology and Museum Anthropology Review, as well as of serving as Interim Editor for the Journal of Folklore Research in 2013, have informed my various writings and lectures on the subject of open access (cited in Jackson and Anderson 2014; Jackson 2018). They also shaped my work in the Open Folklore project, chairing the publications committee of the American Folklore Society, my efforts in a Mellon Foundationfunded study of open access monograph publishing, and in editing the Material Vernaculars book series with the Indiana University Press. That series, while not open access, publishes free-to-readers PDF editions for those who cannot otherwise obtain access to print or digital versions. The era of publishing Museum Anthropology Review in a form that is an echo of Museum Anthropology continued into the time of my directorship of the Mathers Museum of World Cultures. I began as director in January 2013 and that moment marked another transition for MAR.

Prior to 2013, MAR was published by my colleagues and I connected very informally. The IU Libraries helped make that publishing happen, but the journal did not have a formal sponsor or an organizational underpinning. This was a source of concern for me then and I knew that it would have to be resolved in some fashion. Those wondering about why such a structureless or sponsor-less arrangement might be problematic can consider developments with the journal $H A U$ made public during 2018 (Agro 2018; Gershon 2018, Green 2018; Jackson 2018). In the case of MAR, my appointment as director of the museum offered a logical and fruitful solution; one appropriate to MAR's scale and the museum's strategic goals.

With the knowledge of the staff and our partners at the IU Libraries, MAR became, beginning in 2013, the journal of the Mathers Museum of World Cultures. When my time as director concludes, the journal will stay behind and my successor will decide the direction that it takes in service of the museum's mission and of the fields that the museum, and the journal, were created to advance. Between 2013 and 2018 though, I kept the journal pretty closely on the course it had been on since 2008.

I recount these parts of the history of Museum Anthropology Review because they provide context for the direction that I intend to take next. The Mathers Museum of World Cultures has pursued a range of projects aimed at both serving its diverse constituencies and advancing the fields of museum-based ethnography, ethnology, and cultural history. In particular the museum has, as MAR and I also do, worked at the points of overlap between museum anthropology and museum-based folklore and ethnology. Beyond museums as a 
specific focus, the our work has also aimed to advance the field of material culture studies. This approach is also characteristic of the journal and of the academic programs in which I work at Indiana University. In a general way, publishing MAR has definitely contributed to the museum fulfilling its mission as a university-based, research-oriented museum of world cultures- one grounded in ethnographic, historical, and comparative (but not archaeological) methods.

Yet, as I have edited it since 2013, the relationship between the museum's work and the journal's work have been mainly positioned in these broad service-to-the-field ways. The journal continued to review and, when supported by peer-review, publish work from colleagues around the world whether they had any connection to the museum or not. As an advocate for open access journals, particularly those published modestly without the involvement of larger commercial firms, this is an excellent thing. But from my vantage point as director, I am eager to use the journal more actively to advance and share the specific work of the Mathers Museum of World Cultures and its active museum and community partners. I want there to be more and better venues for all scholars to submit their work for publication in open access ways, ideally without author-side fees. But as I enter my fourteenth year as an editor, spread across three journals, I am ready for a period in which I am not faced with an unending flow of unsolicited submissions arising from the great many diverse contexts in which museum anthropology, and its disciplinary congeners, are practiced. I love that diversity, but it is a time for a change and the museum will, for the period immediately ahead, be best served by a more focused approach in which alignment with the ongoing work of the museum and its broad network of collaborators is used as one benchmark for inclusion.

What will this look like? If Museum Anthropology provided the template for Museum Anthropology Review between 2008 and 2018, an inspiration for the next few years might be the rich Minpaku Anthropology Newsletter published by the National Museum of Ethnology in Osaka, Japan. This publication regularly shares diverse scholarly works of interest to scholars and museum practitioners around the world, but anyone reading it can readily see that the works that are published in its pages arise from the relationships and projects of the museum that publishes it. The publication advances the museum as it also makes broader contributions to museum-based ethnology. House journals are a venerable and honorable practice in, and beyond, museum scholarship. While MAR will probably never rival the production values found, for instance, in beloved museum magazines such as Gilcrease Journal or El Palacio, I am confident that we can continue to publish robust scholarship that, at the same time, helps scholars and communities better know the remarkable projects that are happening at the Mathers Museum of World Cultures and in the museums and community organizations-in the US and abroad-with which the museum is partnered. Peer-reviewed articles and various reviews will continue to appear in the journal, but the center of gravity will shift to emphasize the project report genre. Authors are still welcome to write to discuss possible article or review projects but, for the time being, most journal content will arise from invitations to contribute as opposed to the open submission system used in the period between 2008-2018. 
Is the shift permanent? Probably not. MAR has changed already in its history and it very well could shift again. The future of the journal will depend on the evolving needs of the Mathers Museum of World Cultures and the goals set by its leaders and staff. The good news is that the journal's content is permanent, at least as permanent as the talented and preservationminded librarians and staff of the Indiana University Libraries can make it. I take this opportunity to again thank them for their work in support of the journal since its earliest moments.

In conclusion, I also wish to thank the many authors and peer-reviewers who have contributed so substantively to Museum Anthropology Review since its founding. The journal's peer-reviewers in particular deserve special recognition for devoting vast amounts of time to vital labors that are largely hidden from view. Scholarly communication faces many vexing challenges, but the careful and generous reviews that MAR reviewers provide as a gift to the authors that they review, to the readers of the journal, and to the field as a whole are a tremendous source of encouragement to me. Thanks also go to the journal's readers, both known and unknown, to the journal's editorial board, past and present, and to the hard-working editorial assistants who have helped publish the journal since its birth.

\section{Notes}

1. The acceptance rates for my editorship were 88\% (2005), 41\% (2006), 29\% (2007) and $21 \%$ (2008). The overall rate for this period being 36\% (Jackson 2009).

2. Expanding the amount of content published within Museum Anthropology as a toll access journal and AnthroSource as a gated platform would ultimately have the effect of raising revenues or, at least, providing the basis for a case for higher subscription fees. This was not the only major factor in play. There were important sustainability and intellectual property questions that would need to be addressed if sections were going to start publishing, each in their own way, on the open web.

\section{References Cited}

Agro, Hilary (@hilaryagro).2018. “Okay, since there is a ton of confusion happening in the world of anthropology right now (at least online), I'm going to try to put everything in a chronological thread." Twitter, June 13, 2018 to August 22, 2018. https://twitter.com/hilaryagro/status/1021455460409303040

American Anthropological Association. 2019. "Publications FAQs.” Accessed January 15, 2019. https://www.americananthro.org/ConnectWithAAA/FAQListPubs.aspx

Colwell-Chanthaphonh, Chip and Stephen E. Nash. 2008. "Notes from Museum Anthropology's New Editors." Anthropology News 49 (9): 45. https://doi.org/10.1111/an.2008.49.9.45.1 
Colwell-Chanthaphonh, Chip and Stephen E. Nash. 2010. "A Future for Museum Anthropology?" Museum Anthropology 33 (1): 1-5. https://doi.org/10.1111/j.15481379.2010.01069.x

Fowler, Catherine S. 2008. "Museum Anthropology Editorship." Museum Anthropology [Blog] January 15, 2019. https://www.museumanthropologyblog.com/homepage/2008/12/next-editors-ofmuseum-anthropology.html

Gershon, Ilana. 2018. “Pyramid Scheme.” Allegra Lab Accessed January 15, 2019. http://allegralaboratory.net/pyramid-scheme-hautalk/

Green, Sarah. 2018. "The Tyranny of Structurelessness and No End in Sight." Allegra Lab Accessed January 15, 2019. http://allegralaboratory.net/hautalk-the-tyranny-ofstructurelessness-and-no-end-in-sight/

Indiana University. 2008. "IU Bloomington Libraries Publish their First Electronic Journal, Showcasing Faculty Partnerships." Accessed January 15, 2019. http://newsinfo.iu.edu/news-archive/7590.html

Jackson, Jason Baird. 2006. "On the Review of Digital Exhibitions." Museum Anthropology 29 (1): 1-4. https://doi.org/10.1525/mua.2006.29.1.1

Jackson, Jason Baird. 2007. Museum Anthropology Editor's Report. Arlington, VA: Council for Museum Anthropology, American Anthropological Association.

Jackson, Jason Baird. 2008. "Next Editors of Museum Anthropology Named by CMA Board." Accessed January 15, 2019. https://www.museumanthropologyblog.com/homepage/2008/12/next-editors-ofmuseum-anthropology.html

Jackson, Jason Baird. 2009. Report of the Former Editor, Museum Anthropology. Arlington, VA: Council for Museum Anthropology, American Anthropological Association.

Jackson, Jason Baird. 2018. “Community-Based Open Access, Fast and Slow." Allegra Lab Accessed January 15, 2019. http://allegralaboratory.net/community-based-openaccess-fast-and-slow-hautalk/

Jackson, Jason Baird and Ryan Anderson. 2014. "Anthropology and Open Access." Cultural Anthropology 29 (2): 236-263. https://doi.org/10.14506/ca29.2.04

Nichols, Deborah, Bernie Perley, and Oona Schmid. 2015 Why a Collective Portfolio? The History of Principles and Practices of the AAA Publishing Program. Arlington, VA: American Anthropological Association. http://s3.amazonaws.com/rdcmsaaa/files/production/public/2015.03.29 collective final.pdf 
Jason Baird Jackson is the Editor of Museum Anthropology Review and Director of the Mathers Museum of World Cultures at Indiana University where he is also a professor in the Department of Folklore and Ethnomusicology and the Department of Anthropology.

https://doi.org/10.14434/mar.v13i1.26802 